\title{
Teaching the Scrum Master Role using Professional Agile Coaches and Communities of Practice
}

\author{
Maria Paasivaara*†‡ \\ Email:maria.paasivaara@lut.fi \\ *IT University of Copenhagen, Denmark \\ ${ }^{\dagger}$ Aalto University, Espoo, Finland \\ $\ddagger_{\text {LUT University, Lahti, Finland }}$
}

\begin{abstract}
As Scrum seems to be the most popular Agile method at the moment, most universities teaching software development teach it. A Scrum Team consists of a Scrum Master, a Product Owner, and developers. The Scrum Master role is vital in the team. However, looking at the industry, companies have difficulties both in hiring good Scrum Masters and convincing their developers or other personnel to take that role. Agile trainers do offer short Scrum Master training courses. However, we lacking information on how to train Scrum Masters in university education.

In this paper, we report how we arranged a one-semester long Scrum Master training course. During the course, students worked as team Scrum Masters under the guidance of professional agile coaches and collaborated in a Scrum Master Community of Practice.

We collected data by performing 13 post-course semistructured interviews with Scrum Masters and by analyzing the learning diaries of 37 students from three course instances.

Team-specific Agile coaches supported their Scrum Master first by example, then by observing the Scrum Masters in action and providing feedback and ideas, and finally by helping students to reflect. Students found the coaches extremely useful and wished they had utilized their coach more. Scrum Master community of practice worked best when students self-organized, shared practices and tools and provided peer support when facing problems. Finally, students with a non-technical background, as well as female students performed better as Scrum Masters than computer science and male students.
\end{abstract}

Index Terms - software engineering education, capstone course, Scrum

\section{INTRODUCTION}

Scrum [1] continues to be the most used Agile method in industry according to the 14th State of Agile survey conducted by Version One [2]. The survey reported that $58 \%$ of the respondents were using Scrum and 18\% Scrum related variants. As universities aim at providing education that is aligned with industry needs to prepare students for the workplace, teaching agile software development, especially Scrum, is increasingly common [3], [4].

Agile development is mainly taught by traditional lecture courses. As using capstone projects to teach software development in practice has become increasingly popular [5], some project courses have started using Scrum as their software engineering framework that student teams follow in their projects (see, e.g. [3], [6]).

A Scrum Team consists of a Product Owner, a Scrum Master, and developers [7]. In educational projects, the dif- ferent Scrum roles may all be played by students, or some by the course personnel, e.g., Product Owner and Scrum Master roles, while in some cases the Product Owners come from the industry [6].

In this paper, we present a course set-up we have been using at the IT University of Copenhagen in Denmark for three years: The second year bachelor level software development students form the development teams and Master level students take the Scrum Master role, while the Product Owners come from industrial customers that also provide real industrial projects for the team. All projects are required to use Scrum.

We first report how we have arranged the course setup, especially from the point of view of the Scrum Master students. Second, we report our findings based on an analysis of 13 semi-structured interviews with Scrum Master students and 37 Scrum Master student learning diaries during three instances of the course, years 2018-2020.

In this study, we provide findings on 1) how professional agile coaches and student Scrum Masters collaborate in practice, and how the students benefit from this collaboration, 2) how a student Scrum Master Community of Practice works and how it benefits the participants, and 3) whether the background of a student has any effect on his or her performance in the Scrum Master role.

In Section 2, we present related work. In Section 3, we describe the teaching environment and our course set-up. In Section 4, we describe the research methodology used to investigate the Scrum Master students' perspective. We present the results in Section 5, and finally conclude the paper in Section 6.

\section{RELATED WORK}

In this section, we first review the definition of the Scrum Master role, then present related work on the Scrum Master role, and finally discuss how Scrum Masters are trained in the industry.

\section{A. Scrum Master - The Definition of the Role}

According to the Scrum Guide [7] a Scrum Team is a self-organizing and cross-functional team that consists of one Scrum Master, one Product Owner, and developers. The Product Owner is accountable for maximizing the value of the product, while the developers are committed to creating 
a usable increment in each Sprint. The Scrum Master is accountable for establishing Scrum as defined in the Scrum Guide. Thus, the Scrum Master should help everyone to understand Scrum both in theory and in practice.

The Scrum Master is a servant leader, which means that he or she serves the Scrum Team and the rest of the organization. The Scrum Master serves the Scrum Team by coaching the team in self-organization and cross-functionality, by helping the team to focus on creating high-value increments, by making sure impediments are removed, and by ensuring that all Scrum events occur productively and positively within the time-box. The Scrum Master serves the Product Owner by helping to find techniques for product goal definition and product backlog management, by helping to establish product planning, as well as by facilitating stakeholder collaboration. Finally, the Scrum Master serves the whole organization: by leading, training, and coaching in the Scrum adoption, by planning and advising the Scrum implementation, by helping to understand and enact an empirical approach for complex work, and by removing barriers between stakeholders and Scrum Teams. [7]

As can be seen from the list above, a Scrum Master has a lot of responsibilities both on the Scrum Team level, to make the team work well, as well as on the organizational level to first make the Scrum adoption a success and then to keep the whole organization improving. Thus, based on the Scrum Master definition, a person in this role should have at least the following qualities: a) know Scrum and Agile extremely well and be able to teach them to others, b) be a good "people person" and facilitator, and c) be a change leader that is able to plan and lead an agile transformation.

\section{B. Studies of the Scrum Master Role in the Industry}

Even though the Scrum Master role is such an important role in both adopting and using Scrum in an organization, there does not exist much research specifically on the Scrum Master role.

When transitioning to agile a question is that who should become Scrum Masters and what kind of background a Scrum Master should have. In some cases, the agile roles, like the Scrum Master and Product Owner positions, are opened for internal applicants to apply [8]. Often part of the middle managers, like those who have worked as project or line managers, do not have a clear role in the new agile organization [9] and thus might take or be appointed to a role of a Product Owner or a Scrum Master. However, according to a systematic literature review by Dikert et al. [9] there is a challenge to overcome when managers are appointed as Scrum masters: they would need to change their mindset from a traditional, plan-driven, command and control culture to give room for self-organization. For example, according to Dikert et al. [9], in one case, the developers felt that they were being micromanaged by the ex-manager Scrum Masters, and in another case mixing the role of a project manager and Scrum Master created a conflict of interest. Noll et al. [10], suggest based on their case study, that it would be better if former project managers would become Product Owners, instead of Scrum Masters, as the responsibilities of that role are closer to the traditional responsibilities of a project manager. However, this still leaves the question open: Who should become Scrum Masters?

Three papers [10]-[12] have studied the activities the Scrum Masters perform in practice. Next, we briefly present their findings. Noll et al. [10] found in their systematic review of 33 papers nine activities that Scrum Masters performed: process and ceremony facilitation, impediment removal, prioritization, sprint planning and reviewing, estimation, traveling to meet distributed team members, and project management. When compared to the Scrum Guide, only the three first ones in this list (process and ceremony facilitation, impediment removal) should be the Scrum Master's responsibility. Most other activities should be mainly taken care of by the team or the Product Owner. Noll et al. also found that almost half of the studied papers (15/33) reported Scrum Masters holding additional roles, either technical (such as architect, test lead, or developer) or managerial (such as project manager). This means that even though Scrum Master is meant to be a fulltime role, in practice, many Scrum Masters hold other roles and responsibilities at the same time, which might interfere with their Scrum Master role.

Bass et al. [11] studied the tailoring of the Scrum Master role by performing an interview study of eight international large-scale agile organizations. They found that the Scrum Masters played these ten roles: scrum of scrums facilitator, sprint planner, integration coordinator, learning coordinator, heartbeat monitor, process anchor, task estimator, impediment remover, spike process coordinator, and test coordinator. Part of these activities are clearly Scrum Master tasks, like Scrumof Scrums facilitation and impediment removing, but the part should be taken care of by the developers, such as task estimation or test coordination.

The third study on the Scrum Master activities, performed by Spiegler et al. [12], studied the difference between the Scrum Master and developer tasks and how the responsibilities change according to the maturity of the Agile implementation. In their interview study of 53 practitioners in Bosch, the authors found that initially, Scrum Masters may take these nine leadership roles: Method Champion, Disciplinizer on Equal Terms, Coach, Change Agent, Helicopter, Moderator, Networker, Knowledge Enabler, and Protector. While the team matures, the Scrum Masters transfer some of the roles to the team. According to Spiegler et al., this transfer occurs in three steps: first, the Scrum Master servers as a role model by performing all roles while the team members observe, second, the Scrum Master stops playing certain roles and creates a leadership gap that the team members could take over, and in the third step team members take care of most of the roles, while Scrum Master helps when needed and plays some of the roles difficult to move to the team like Moderator and Protector.

As could be seen from these three studies of the activities the Scrum Masters perform in practice, the Scrum Masters in 
the industry do even more and broader tasks than asked by the Scrum Guide. This seems to indicate both the importance of the Scrum Master role in an agile organization, but also that Scrum Masters are required to have quite broad knowledge and skills. Here we come to the question we study in this paper: How to train students for the Scrum Master role?

\section{Training Scrum Masters in Industry}

Based on the experience reports of several companies that describe their agile transformation journeys, the companies typically either send their people to Agile training courses or organize in-house training courses for their people. The systematic literature of large-scale agile transformations states that one of the success factors for Agile transformations is providing sufficient training on agile methods [9].

In the industry the Scrum Master training is quite straightforward: According to Scrum.org [13], there are two levels of 2-day Scrum Master training courses. "Certified Scrum Master" courses are offered by many Scrum trainers. The first level training teaches the basics of the Scrum framework and the second level training aims to teach how to apply the Scrum framework to solve more complex problems in the real world. After each of these courses, a test can be taken and a passed test will give a certificate to the student. After these two levels, Scrum.org still offers a third level test and a certificate after that, which proves that the holder has "a deep understanding of the application of Scrum, Scrum practices, the Scrum Values", and has "the ability to apply Scrum in a variety of complex team and organizational situations". Persons achieving this certificate should, besides understanding and being able to apply Scrum, be able to also "mentor and coach people or teams who are adopting Scrum".

These short training courses and certifications seem to be a good business both for the trainers and for the certification body. Companies willing to send their people to these training courses can be sure that their people get the basic knowledge. However, applying that knowledge in practice is more difficult. Even the authors of the Scrum Guide have stated that Scrum is simple to understand but difficult to master. Therefore, it is recommended that after taking training courses, agile coaches would coach the teams and agile roles as they learn by doing [9].

Thus, it seems that in industry the basic path for becoming a Scrum Master would be taking a basic training course and then starting working as a Scrum Master while being mentored and coached by an Agile coach. However, in practice companies would like to hire Scrum Masters that they can put directly in a Scrum Master position: Scrum Masters that in addition to the basic knowledge, also have at least some "mastering" of the role that comes through practice and with the help of good coaching.

In this paper, we present how we in university education could train students that would have the necessary knowledge and skills to directly take on the role as Scrum Masters in industry.

\section{SCRUm MASTER TRAining COURSE}

In this section, we briefly describe the Scrum Master Training course organized at the IT University of Copenhagen, as run during the spring term 2018-2020. The course was organized in connection with a project course mandatory for the second-year bachelor students. Therefore, we briefly describe both courses here. The courses have been inspired by similar courses at Aalto University in Finland (described, e.g., in [6]), where the main teacher of the course described here has been working previously and has participated in teaching those specific courses at Aalto.

The main emphasis of the Scrum Master course is on the practical work as a Scrum Master for a team that is building working software according to the requirements of an industrial customer using the Scrum method. Passing the course gives a student 7,5 ECTS which means approximately 200 hours of work.

Next, we describe the stakeholders and their roles in the projects, the course structure, and the teaching methods, as well as the learning goals of the Scrum Master course.

\section{A. Students and Teams}

We created two separate courses: a project course for bachelor level software development students that work as developers in a Scrum team, and a Scrum Master training course for master level students that are trained to be Scrum Masters.

During spring 2018 we carried out a pilot course with two Scrum teams. Each team had a 6-7 students taking the B.Sc. level software engineering project course and working as developers in the projects, while the two Scrum Master students took a Master level course.

As the pilot was successful, we rolled out the bachelor level course in 2019. It was mandatory for all 130 software development B.Sc. students, which we organized into 16 teams. The Scrum Master course was offered as an elective course for all Master level programs at the university.

In 2020, the same structure was kept with 140 bachelor level students organized into 18 teams. In this instance of the course five teams worked as distributed teams between Denmark and Belarus and one fully located offsite in Belarus, as we had around 25 students that participated in the course from five universities from Belarus as part of a joint Erasmus+ project $\mathrm{MaCICT}^{1}$.

Altogether, we had 37 Scrum Masters taking the course during the three instances of the course: two in 2018, 17 in 2019 and 18 in 2020.

Teams are formed in a team self-selection event [14] by the students themselves. While forming the teams, we recommend the students to take into account especially their course and work schedules, i.e., they should have a possibility for weekly team work sessions, preferably worth two working days. Both

\footnotetext{
${ }^{1}$ Modernisation of Master Curriculum in ICT for Enhancing Student Employability (MaCICT), for more information see the project web site: http://macict.eu/
} 
team members and Scrum Master students participate in the self-selection event that is facilitated by the course personnel.

\section{B. Clients and Topics}

Prior to the course, the teacher collects plenty of topic proposals from companies. The idea is that each topic is useful for the company proposing it and the project results can be taken into use after the project. Each project has a client representative that works as a Product Owner for his or her team and actively collaborates with the team weekly. The Product Owner participates, e.g., in sprint planning meetings and sprint reviews, as well as provides their feedback for grading.

The companies prepare short project proposals and we schedule interviews between the student teams and those clients they are most interested in working with. At the end of this match-making event, both student teams and clients prioritize their partner choices and we run a matchmaking software based on the stable marriage algorithm, that matches the projects and student teams.

\section{Course Structure and Teaching Methods}

Both courses start with an introductory lecture on Scrum. The teams are formed in the end of the first lecture. Scrum Masters have intensive Scrum Master training workshops worth two working days, organized by professional agile coaches and trainers. The second lecture contains the match making event between the student teams and the Product Owners.

All teams practice Scrum in a 4-hour Scrum LEGO simulation (see e.g., [15]) where the Scrum process is simulated by running 3-4 Sprints in which the programming work is replaced by building LEGOS. In this simulation, the whole team works together as a Scrum team, the team Scrum Master practices his or her role for the first time and receives guidance from an agile coach.

After the Scrum simulation, the teams are ready to start their projects with their real customers. Scrum Master students start guiding their own Scrum teams. A professional Agile coach is assigned to each team to support the team and especially the team Scrum Master in their new role during the whole 3-month project. All teams were required to use Scrum as defined in the Scrum Guide (2017 version) [16].

During the projects, each Scrum Master student is actively cooperating with his or her team, the customer, and the coach. Besides guiding the team regarding Scrum, the Scrum Master student is expected to actively support his or her team in their daily activities, e.g., during different meetings and while analyzing and solving software engineering and team workrelated problems.

During the projects, each Scrum team participates in regular project reviews with all stakeholders, including the Product Owner, the coach, and the teachers. In addition, the course organizes experience exchange sessions between the teams and encourages the Scrum Masters to form a Scrum Master Community of Practice. These sessions help students to share experiences with other teams and other Scrum Masters and that way deepens their learning on specific topics and receive peer guidance when facing challenges.

The course ends with final reviews organized separately for each team and their stakeholders. Grading is based both on reviews and on learning diaries that students write during the whole semester.

Finally, the course culminates in the celebration event, where all teams present their projects, the best teams receive a quality award from the course sponsor company, and all stakeholders celebrate with the students the finalizing of the projects.

\section{Scrum Master Learning Goals}

The main learning goals of the Scrum Master course are:

1) Being able to apply the Scrum method in practice as a Scrum Master and reflect over its usage.

2) Plan, organize and conduct collaboration with own Scrum team, industrial customer, and an agile Coach

3) Identify and analyze practice problems faced in the project (from the Scrum Master point of view), compare and discuss different solutions, execute the chosen solutions and discuss the pros and cons of the practices and solutions.

\section{Methodology}

\section{A. Questions}

To support the learning process of the Scrum Master students, we experimented with two new practices: 1) teamspecific professional agile coaches and 2) a Scrum Master Community of Practice. In this paper, we study how these new practices worked out from the student point of view. In addition, we made the Scrum Master course open to students without computer science background. We study how that worked out.

In this paper we aim to answer the following questions:

Q1: How do professional agile coaches and student Scrum Masters collaborate in practice, and how do the students benefit from this collaboration?

Q2: How does a student Scrum Master Community of Practice work and how does it benefit the participants?

Q3: Does the background of a student have an effect on his or her performance in the Scrum Master role?

\section{B. Data Collection}

The data consists of three elements: 1) 13 semi-structured interviews of Scrum Master students, 2) 37 learning diaries written by the Scrum Master students, and 3) Scrum Master students' final grades and their study programs.

1) Interviews: After the second instance of the course, we invited all 17 Scrum Master students to individual interviews to collect their opinions and feedback. The interviews were conducted right after the course final exams by the course teaching assistants.

Participation in the interview was voluntary. 13 Scrum Master students agreed to participate in the interviews that 
took $10-19$ min per student and $171 \mathrm{~min}$ in total. Interviews were transcribed by a professional transcription company. The main purpose of the interviews was to collect student feedback on the course and understand the Scrum Master students' learning and collaboration with different partners. The questions covered these seven topics: a) what they felt were the most valuable things they had learned during the course, b) what were the biggest challenges they faced as Scrum Masters during the projects, c) what they felt was best in the course, d) how collaboration with their Product Owner, coach, and the team had worked, both positive and negative sides, e) whether they would do something differently if they could start the course again, and finally f) how the course could better support their learning.

2) Learning Diaries: One part of the Scrum Master student grading was their learning diary, which the student should update at least before each of the three mandatory review meetings. The learning diary document should start with the student's individual learning goals for the project. After that, the entries before each of the three review meetings should contain a) individual learning goals for the $\operatorname{sprint}(\mathrm{s})$, b) the main points that the student learned during the previous sprint(s) including at least three educational observations related to the use of Scrum or other work methods, each point containing also discussion/reflection, and c) a short summary of student's own contribution to the project since the previous review. Finally, the last entry of the diary should contain final reflections on the project and learning during the whole course, including a comparison to the learning goals.

As the learning diary was a compulsory part of the course, we received diaries of all 37 students. A typical length of a diary was 8-15 pages.

3) Grades and study programs: The final grades and information on the study program of all Scrum Master students were collected from all three instances of the course. The Danish system includes five accepted grades 2 (lowest acceptable), 4, 7, 10, and 12 (highest). These were converted to 1 (lowest acceptable) to 5 (highest) system to make it easier to calculate averages.

\section{Data Analysis}

The interviews and learning diaries were analyzed by qualitative coding. The main codes used were "coach collaboration" and "CoP". In addition, quotations from the interviews were chosen to illustrate the main findings.

\section{Limitations}

We asked the teaching assistants to perform the interviews, as we expected that they would be more "neutral" than teachers, and students would feel free to report also about negative experiences with them. However, we recognize that this is still a limitation, as a student might answer more positively when a teaching assistant performs the interview than if an outsider would do that. Another limitation is that we were able to interview students only during one instance of the course and not during all three instances.

\section{Results}

In this section, we present answers to our three questions. Each question is answered in a separate section.

\section{A. Coaching}

In this section, we answer Q1: "How do professional agile coaches and student Scrum Masters collaborate in practice, and how do the students benefit from this collaboration?"

Agile methods avoid prescribing exact ways of working, instead, they emphasize a mindset of adapting to the situation. However, it is difficult to explain how such a mindset should be applied, thus agile practices are best learned by doing. Coaching teams while they apply agile methods in practice was found to be essential for the success of an agile transformation [9].

A few books have been written about agile coaching (e.g., [17], [18]) and several agile scaling frameworks recommend coaching. For example, the Large-Scale Scrum framework (LeSS) states that "A LeSS adoption chance of success is dramatically higher when the organization ensures the appropriate level of coaching." [19]. LeSS recommends three levels of coaching: 1) organizational coaching, where coaching aims to improve the organization and its' structure, 2) team coaching, during which a coach works with one or a few teams and aims to improve their teamwork and practices. 3) technical practices coaching, which aims to improve the technical practices and the adoption of agile development techniques in a team [19].

As coaching is such an important supporting element while learning agile, we found it important to support our teams and their Scrum Masters by appointing each team a professional agile coach. Of the three coaching levels mentioned above, team coaching was found to be suitable to our situation.

As agile coaches, we searched for persons that worked in the industry as agile coaches or as Scrum Masters, and who were willing to coach a student Scrum team. Each coach got a small remuneration from the university. Most of the coaches were very experienced and were eager to share their experiences with students. Each coach was expected to spend around forty hours in total to support their team. Coaches were also asked to participate in the three review meetings with their team and give the team feedback from a coach's point of view, i.e., how the team applied Scrum and agile, as well as provide their input to grading.

Student teams were asked to contact their coach and agree with the coach on how they wished to collaborate with him or her. We did not define an exact form of collaboration, as we wanted to give flexibility to each student team and their coach to find the best form of collaboration that would fit their way of working.

1) Collaboration with the coaches: The collaboration took place in different ways. Some coaches were very active in the beginning: they gave small Scrum trainings to the team and the PO, as well as demonstrated how a Scrum Master works by acting as a Scrum Master in some of the first Scrum events.

"During the first sprint, all Scrum events our coach was doing them, then the next week I was doing all events, but the coach 
was watching me and giving me feedback what I should improve, so basically during the first sprint, I learned all that I have to do during Scrum. [...] That helped me a lot."

— Interviewed Student, 2019

Later on, when switching to the student Scrum Master, the Scrum Master and the coach could go through the facilitation plan for the next event, get feedback on the plan, and then, after the event, receive feedback from the coach, who had either observed the event or, if not being able to be there just have a discussion with the Scrum Master afterward.

"He observed the team [...] he commented on what I was doing good, what I could improve, which was very helpful, and I would not have wanted to miss that. I think I learned a lot from that, getting the feedback."

- Interviewed Student, 2019

Some coaches and Scrum Masters agreed weekly meeting slots, face-to-face or online, during which the Scrum Master could ask questions and get feedback. Teams often invited the coach to their chat channel, where they could ask questions from the coach.

"We made a Slack channel and we invited him [coach] to this channel because any time I had a question I could call him or write him about Scrum or when I had problems with the team or facilitating whatever, so he was there."

— Interviewed Student, 2019

A few of the coaches worked with the company that offered the project and that way the team could have an in-house coach. Especially those teams that worked in the customer premises and had an in-house coach had a very privileged position, as they could meet their coach daily while working in the office.

"The company turned out to be a great working place with a lot of stimuli [..] Scrum coach was there working in general and he was available to us almost 24/7, even on the weekends.

[...] He voluntarily attended a lot of our meetings, [...] he saw us present before the review, he gave us excellent feedback, he proposed so many tools that we used, [...] just amazing" - Interviewed Student, 2019

The coaches worked by giving the Scrum Master students suggestions or helping the Scrum Master student to reflect.

"I had a lot of comments and suggestions from my coach [...] he made like on-point comments, not something irrelevant [...] he wasn't like controlling or overseeing over my shoulder, he was just, "maybe you can try this" and it was up to me to decided whether I want to try out that or whether I want to try out something different [...] so this is really nice

- Interviewed Student, 2019

"He [the coach] was willing to take some coffee meetings, able to sit down and talk about the reflection and learn from him, that he gave some opinions of his and he gave me room to reflect on it myself and learn from it and use it myself. That was nice."

$$
\text { — Interviewed Student, } 2019
$$

The Scrum Master students found the coaching highly useful.

"Coach was perfect. [...] Really helpful, lots of ideas. [...] He wanted to hear what I think about the process and then he gave his ideas." - Interviewed Student, 2019

Some even mentioned that as the best thing about the course:

"All these different coaches, Agile coaches. I saw a lot of different opinions and a lot of different ways they did things, and I think having more than one opinion, it was very valuable." — Interviewed Student, 2019
2) Challenges with coaching: Even though the Scrum Master students were very happy about the collaboration with their coach, many of them mentioned in the end of the course that they wish they had used the coach more.

"I've learned so much from every conversation I've had with him. I just wish I had used him more in the sense that I would have contacted him more, like quick talks, like how do I do this and this or like reflecting on certain elements, I wish I had been better at using him as a resource."

— Interviewed Student, 2019

The reason for not using the coach enough seemed to be that the students were a bit too shy about contacting the coach and some even said that they were not sure how they should use their coach. Some coaches were very proactive and initiated meetings, while other coaches expected that the students contact them when they are needed. In addition, as most coaches were working full time in the industry, they were not always available right away, when a student team or a Scrum Master would have liked to have a meeting with him or her on very short notice.

To avoid this unnecessary confusion, both students and coaches suggested that we write short instructions on how to use a coach and suggest agreeing on regular meetings with the coach right from the beginning. A suitable rhythm for a coach to meet with the team could be once in a sprint, i.e., every second week. Whereas a coach could meet with the Scrum Master once a week. These meetings do not necessarily need to be physical face-to-face meetings, but an online meeting or a phone call can work as well. Thus, for the current version of the course, we have taken into use a short written suggestion on "how to use a coach".

3) Coaching, recommendation: Based on our findings, we can recommend: i) Appointing a professional agile coach for a student Scrum team is highly useful, especially from the student Scrum Master's point of view. ii) Make clear for the students how they can benefit from an agile coach iii) Make clear both for the coaches and the students the expectations for coaching and encourage them to agree on a regular meeting rhythm in the beginning.

\section{B. Scrum Master Community of Practice}

In this section, we answer Q2: "How does a student Scrum Master Community of Practice work and how does it benefit the participants?"

When scaling agile software development, Communities of Practice (CoPs) have been proposed as a possible solution for learning and knowledge sharing between individuals with similar roles, e.g., for Scrum Masters [20]. Some agile scaling frameworks, e.g., Scaled Agile Framework (SAFe) [21] and Large Scale Scrum (LeSS) [19] recommend CoPs for learning and coordination.

A CoP is defined as "a group of people who share a concern, a set of problems, or a passion about a topic, and who deepen their knowledge and expertise in this area by interacting on an ongoing basis" [22]. CoPs have been applied in a wide variety of industries and contexts [22], [23]. 
Agile companies have used different kinds of CoPs, e.g., Coaching CoP, Developers' CoP, and Functional Verification CoP [24]. The role-based CoPs, especially for Scrum Masters, seem to be the most common in the industry. Ideally, a Scrum Master CoP is a peer support group for Scrum Masters, e.g., a group of Scrum Masters that work in the same organization that meets regularly and learns to exchange experiences and solve problems together. For example, the fellow Scrum Masters might have faced similar challenges in their teams and can brainstorm solutions together. In industry, CoPs often need support from the management in the beginning, to get the CoP culture started, but later on, people in an agile organization build CoPs on their own when they see a need for that [24].

Next, we describe how Scrum Master CoP was used in the course, how it evolved, and what were the benefits achieved and challenges faced.

1) CoP, first course instance: During the first instance of the course, the course personnel did not suggest a Scrum Master CoP, as we had only two teams and thus two Scrum Masters. However, those two Scrum Masters naturally build a CoP: they started meeting over coffee regularly every week and shared their experiences and concerns. That turned out to be a great support forum for them both. The Scrum Masters even decided to extend this experience sharing with their teams by switching Scrum Masters for one retrospective, i.e., conducting one retrospective meeting for each other's teams. They found this very useful, like one of the Scrum Masters describes:

"This experience was very beneficial both for me and in my perception also for the other team. On the one hand, when they expressed process-related issues that they had encountered, I could in most cases bring up ideas for how our team handled similar situations for them to discuss. On the other hand, it was very insightful for me to witness their approach to combat different issues firsthand.” — Learning diary, 2018

2) CoP, second course instance: Based on the positive experiences during the first instance of the course, and also after studying how useful CoPs have been in the industry, during the second instance of the course, we decided to encourage the Scrum Master students to build a Scrum Master CoP. We presented the idea to the students and decided to use a regular lecture slot, that was not needed for lectures when projects started, to organize Scrum Master CoP meetings. Altogether we organized seven CoP meetings during the semester. To each $\mathrm{CoP}$ meeting, the teacher invited one of the industrial Agile coaches, who facilitated the session. We often used the format of Lean Coffee, i.e., Scrum Masters brought the topics and questions they had, the topics were briefly presented, prioritized by dot voting, and then discussed together in the priority order. The students that participated found these CoP meetings highly useful.

"I really liked them [CoP meetings] [...] They kind of worked in a nice way where we could share the knowledge between Scrum Masters, it was actually really nice."

— Interviewed Student, 2019

In the CoP, the Scrum Master students could share their problems and get suggestions on how to solve them, as well as hear new ideas for what to try out with their own team based on what the other Scrum Masters had tried out with their teams, e.g., ideas for team building or techniques for organizing retrospectives.

"I have been attending the community of practice meetings to seek inspiration. From the CoPs, I, e.g., learned about "reliving" the last sprint through exercises."

— Learning Diary, 2019

However, only a small part of the Scrum Masters participated in the CoP sessions. One major reason for the lack of participation, according to the Scrum Masters, was that on that specific day of the week most developers (i.e., bachelor students) did not have other courses and many teams had reserved that whole day for working together and for organizing Scrum events, like sprint planning, review, or backlog refinement. Therefore, the Scrum Masters of those teams were needed by their teams. Luckily, the experience sharing did not limit to the CoP meeting but happened also informally when the Scrum Master students met in the university building, as well as through a Facebook group they created for the Scrum Master CoP.

"We worked a lot together [with other Scrum Masters], have been talking together in the hallways, although we haven't had CoPs every week, we have shared experiences and that has

helped a lot." — Interviewed Student, 2019

3) CoP, third course instance: On the third instance of the course, we decided to continue encouraging students to build the Scrum Master CoP. However, as the official lecture slot could not be moved from that week day when most teams worked together on their projects, we decided to have a different approach: The teacher just introduced the $\mathrm{CoP}$ idea and gave the whole responsibility of organizing the CoP sessions to the students. That way the students could both take more responsibility for organizing the activity and also fit flexibly the meetings with timeslots that could work better for most Scrum Masters.

This solution turned out to work well. Several students took an active role in organizing the CoP meetings and one even asked the teacher if she could put more effort into facilitating the $\mathrm{CoP}$ as her own team was doing fine, to which the teacher agreed. This CoP turned out to be very self-organized. They organized meetings on a need basis when some Scrum Master suggested a topic to discuss and asked if others had time to meet.

"Although we did initially encounter some challenges, due to varying schedules, preferences in communication tools, limitations imposed by the lockdown, and a lack of clarity as to how the practice could help us reach our learning goals, the collaboration between the Scrum Masters proved to be a beneficial learning experience, as we were able to share useful advice which we could then pass on to our teams."

$$
\text { - Learning Diary, } 2020
$$

Mainly, the topics to discuss were challenges and other Scrum Masters gave advice and shared how they had worked in a similar situation. Other topics to discuss were, e.g., the SM role and responsibilities, understanding Scrum, team building activities, communication, tools, collaboration with the PO and coaches, and course requirements. 
"I made use of the CoP to investigate how the other SMs used the burn-down and burn-up charts as a tool. [...] One of the SMs shared that he showed it briefly in the start of the daily stand-up meetings, I thought this sounded like a good idea and I, therefore, adapted this." — Learning Diary, 2020

"During one of the COP's I asked my fellow SMs if they could recommend any other methods for the retrospectives, and I was advised to look at "Focused on feelings" and "1-2-4-all"."

— Learning Diary, 2020

This Scrum Master CoP even collected a "Tips and Tools" document, where they saved useful material for the Scrum Masters. Links included videos that explain some agile concepts in practice, such as user story writing, and a list of tools: both software tools, as well as facilitation tools, e.g., for organizing retrospectives.

"We also began sharing some of our ideas, suggestions, and tips in a folder in Google Drive, which I would argue has helped increase transparency in our collaboration, as well as create a more inclusive environment." — Learning Diary, 2020

Due to Covid-19 related lock down, the physical university spaces could be used only at the beginning of the semester. Thus, after the first face-to-face meeting also the Scrum Master CoP met only online. That could be seen as beneficial, as participation was not limited to only those who had time to travel and meet face-to-face, thus a much bigger part of the Scrum Masters participated.

"Overall, the key lesson from the SM CoP has been seeing the benefits of having a community to get inspiration from and to discuss problems with. The support from the SM CoP has been important for me in this project." - Learning Diary, 2020

4) CoP: recommendation: Based on our findings, we can recommend to the teachers considering using $\mathrm{CoPs}$ the following points:

i) Scrum Master CoP provides a valuable peer learning and support opportunity for the students. We can warmly recommend this practice. It has been clearly visible that Scrum Masters and their teams benefited a lot from this sharing possibility: They learned new practices and tools that they could try out in their teams. Scrum Master students used the $\mathrm{CoP}$ as a support group when they had problems and needed help. The skill of acquiring knowledge and experimenting is fundamental in Scrum. A CoP supports building these skills.

ii) Make crystal clear the purpose of the CoP and the benefits to the students. During the second instance of our course, this was not made clear enough and students that have many priorities easily down prioritize events that they find less important or which purpose they do not fully understand. Especially, explaining how a CoP can support their learning goals would be important.

iii) Build the Scrum Master CoP on self-organization. In industry, the CoPs are rooted in self-organization: those people engage in CoPs that have a passion to learn or contribute. During the third instance of the course, we gave the whole responsibility of organizing the CoP to the students, which paid off. Several passionate students took together with the responsibility of organizing the $\mathrm{CoP}$ and enough Scrum Masters actively participated, which benefited all. By self-organizing, the students also learn that this is how it is done in the industry and the active students even learned how to organize and facilitate a CoP.

\section{Student Backgrounds}

In this section, we answer our final question, Q3: "Does the background of a student have an effect on his or her performance in the Scrum Master role?"

In industry, there has been discussion on Scrum Master background, e.g., whether a Scrum Master would benefit from a technical background, or if some other background would be better. Like our literature review showed, middle managers, who do not have a clear role in agile, take Scrum Master positions when their company moves to agile. However, in practice that might not be beneficial for the team, if the manager still keeps managing.

1) Master Programs: Even though the course was open to students from all Master's Programs at ITU, the computer science students had the first priority, as the course was organized by that department. However, every year we could take a few students from other study programs. Especially students from Digital Innovation and Management (DIM: 3 students in 2019 and 7 students in 2020) and Software Design (SD:3 students in 2020) Master programs were eager to take this course. DIM program does not require a technical bachelor's degree for admission, while SD students must have a bachelor degree in a non-software area. DIM program concentrates on digital change and innovation. The students in that program are expected to get a deep understanding of the complex interplay between people, organizational processes, and digital technologies. The SD program is aimed only to those students that do not have an IT-related undergraduate degree but wish to develop skills and knowledge within IT to combine with the skills from the undergraduate degree. This program focuses on business needs and the students will work on projects concerning the design, development, and maintenance of software.

Students from both of these programs that took the Scrum Master course explained that this Scrum Master course fits their studies perfectly. The DIM students even hoped that we could give more places in the Scrum Master course to students from their program in the future. A few of them explained that the Scrum Master role is exactly the kind of job they are planning to do when they graduate.

"Next semester, the Scrum Master position should definitely be open not only to the computer science people, because [...] I

know that the DIM students, they really want [...], this is what they are studying, project management"

— Interviewed Student, 2019

2) Comparing Students with Different Backgrounds: When comparing how students with different backgrounds performed in this course within this sample of students during the two last instances of the course, we could notice a clear difference. We chose for this analysis only two last instances of the course, as they had a larger number of students, as well as left out the student that participated from Belarus and was graded there. Thus, we had 34 students, 17 in each year, out of which $38 \%$ were females and $41 \%$ had a non-technical background. 
Surprisingly, the students with non-technical background performed on average better than computer science (CS) students, i.e., DIM and SD students received better grades ${ }^{2}$ (4.23/5) than CS students (3.8/5). In addition, female students achieved better grades (4.01/5) than males (3.81/5). Finally, if we look at the female students with non-technical backgrounds (i.e., DIM and SD) they did even better (4.83/5).

These results indicate that students with non-technical backgrounds may suit well as Scrum Masters and that the Scrum Master role fits well for females. A few of the female students even mentioned after the course that the course made them realize that the Scrum Master role could very well be their future job role.

"I am very interested in working as a Scrum Master, as it is something that is exciting to me and I think it plays to my strengths" — Learning Diary, 2019

In the interviews, we asked whether the students felt they had enough background knowledge to take this course. Almost all answered that they either had enough knowledge or got adequate knowledge during the first workshops and lectures. However, a few students with non-software development backgrounds wished they had known a bit more about the software development terminology before they started the project to be able to better understand the conversations in the team. For example, they mentioned that technical knowledge could have helped them in the sprint planning meetings to know when to stop a conversation and when a conversation should be let to continue.

"I didn't know what it meant, for example, pushing and pulling from GitHub. I learned that because I asked like "Hey, what is it when you say I'm gonna push, I'm gonna pull from GitHub?" And they explained and I got it. [...] Especially during the sprint planning, when you talk to the PO about what they have to do and all that, it can be great to just know what the conversation is about." — Interviewed Student, 2019

However, even students with CS background that did not have working experience yet found it difficult to facilitate when their teams were dealing with new technical topics:

"...sprint planning part, where we had to estimate and it was a challenge for me [...] so not being familiar with what they are discussing but still help them decompose the task. So, I could just help putting questions." — Interviewed Student, 2019

These findings support our earlier results, that a Scrum Master does not need a technical background. However, knowing the basic technical terminology, that the team is using, could help the Scrum Master to better understand and facilitate the team.

3) Student background related recommendations: Based on our findings, we can conclude the following: i) Scrum Masters do not need a technical background while understanding the basic technical terminology is helpful. ii) Students with a nontechnical background may suit even better as Scrum Masters than computer science students. iii) Scrum Master role fits well for females. These points would be interesting to study further also within Scrum Masters working in the industry.

\footnotetext{
${ }^{2}$ The grades are converted from the Danish grading system to $1-5$ system where 1 is the lowest acceptable grade and 5 is the highest grade.
}

\section{Summary AND CONCLUSIONS}

In this paper, we discussed how we arranged a semesterlong Scrum Master training course, during which the students worked as team Scrum Masters for bachelor level students under the guidance of professional agile coaches and collaborated in a Scrum Master Community of Practice. We wanted to study how these new experiments, professional coaches, and the CoP worked in practice and how students benefited from them. The main finding was that both experiments were beneficial for the students and we plan to continue using them. In addition, we identified what did not work ideally, and how these practices could be improved during future course instances.

We can warmly recommend appointing professional agile coaches to support student Scrum Masters. However, it would be important to make clear for the students how they can benefit from coaching, align the expectations about coaching between the student and the coach and encourage them to arrange regular meetings throughout the semester. Otherwise, the student might not realize to fully utilize the coach. We noticed that coaches supported the Scrum Master students in many ways: by demonstrating how a Scrum Master works, observing student Scrum Masters in action and providing feedback and ideas, and finally helping students to reflect.

Organizing a Scrum Master CoP was an experiment for which we got the idea from the first two Scrum Masters that provided regular peer support to each other. During the following instances of the course, we took Scrum Master CoP as a part of the course and noticed that building the CoP with self-organization provided the best results. The purpose of the CoP is easily unclear for the students, thus the benefits and the purpose need to be clarified for the students, otherwise, the CoP will not take off. Eager students that take initiative and want to contribute should be encouraged to do that.

As the third topic, we studied how the student's background affects his or her performance as a Scrum Master. To our surprise, we noticed that students with non-technical backgrounds performed better than computer science students. In addition, the Scrum Master role fitted extremely well for the female students. This indicates that we might find the best Scrum Masters outside of computer science. Thus, we should offer Scrum Master courses to those students that have good social skills and are interested in working with people. That way we can educate good Scrum Masters to industry. Studying the Scrum Master's background in the industry would be an interesting future research topic. Finally, female students both succeeded as well as Scrum Masters and liked their role so much that several even mentioned finding that role as a lucrative future career. This means that we should market the Scrum Master role to girls to get more females to the IT sector, as that certainly would be beneficial for the agile teams.

\section{REFERENCES}

[1] K. Schwaber and M. Beedle, Agile software development with Scrum. Prentice Hall Upper Saddle River, 2002, vol. 1.

[2] "14th annual state of agile report," https://www.stateofagile.com. 
[3] D. Damian, C. Lassenius, M. Paasivaara, A. Borici, and A. Schröter, "Teaching a globally distributed project course using scrum practices," in Collaborative Teaching of Globally Distributed Software Development Workshop (CTGDSD), 2012. IEEE, 2012, pp. 30-34.

[4] V. Mahnič, "A capstone course on agile software development using scrum," IEEE Transactions on Education, vol. 55, no. 1, pp. 99-106, 2012.

[5] R. F. Dugan Jr, "A survey of computer science capstone course literature," Computer Science Education, vol. 21, no. 3, pp. 201-267, 2011.

[6] M. Paasivaara, J. Vanhanen, and C. Lassenius, "Collaborating with industrial customers in a capstone project course: the customers' perspective," in 2019 IEEE/ACM 41 st International Conference on Software Engineering: Software Engineering Education and Training (ICSESEET). IEEE, 2019, pp. 12-22.

[7] J. Sutherland and K. Schwaber, "The 2020 scrum guide," 2020. [Online]. Available: https://www.scrumguides.org/scrum-guide.html

[8] M. Paasivaara, "Adopting safe to scale agile in a globally distributed organization," in 2017 IEEE 12th International Conference on Global Software Engineering (ICGSE), 2017, pp. 36-40.

[9] K. Dikert, M. Paasivaara, and C. Lassenius, "Challenges and success factors for large-scale agile transformations: A systematic literature review," Journal of Systems and Software, vol. 119, pp. 87-108, 2016.

[10] J. Noll, M. A. Razzak, J. M. Bass, and S. Beecham, "A study of the scrum master's role," in Product-Focused Software Process Improvement, M. Felderer, D. Méndez Fernández, B. Turhan, M. Kalinowski, F. Sarro, and D. Winkler, Eds. Cham: Springer International Publishing, 2017, pp. 307-323.

[11] J. M. Bass, "Scrum master activities: Process tailoring in large enterprise projects," in 2014 IEEE 9th International Conference on Global Software Engineering, 2014, pp. 6-15.

[12] S. Spiegler, C. Heinecke, and S. Wagner, "Leadership gap in agile teams: How teams and scrum masters mature," 122018.

[13] "Scrum.org homepage," https://www.scrum.org.

[14] S. Mamoli and D. Mole, Creating Great Teams: How Self-selection Lets People Excel. Pragmatic Bookshelf, 2015.

[15] M. Paasivaara, V. Heikkilä, C. Lassenius, and T. Toivola, "Teaching students scrum using lego blocks," in Companion Proceedings of the 36th International Conference on Software Engineering. ACM, 2014, pp. 382-391.

[16] J. Sutherland and K. Schwaber, "The scrum guide," 2017. [Online]. Available: http://www.scrumguides.org/

[17] L. Adkins, Coaching agile teams: a companion for ScrumMasters, agile coaches, and project managers in transition. Pearson Education India, 2010.

[18] R. Davies and L. Sedley, Agile coaching. Pragmatic Bookshelf London, 2009.

[19] "Large-scale scrum homepage," https://less.works/.

[20] C. Larman, Practices for scaling lean \& Agile development: large, multisite, and offshore product development with large-scale scrum. Pearson Education India, 2010.

[21] "Scaled agile homepage," https://www.scaledagileframework.com.

[22] E. Wenger, R. A. McDermott, and W. Snyder, Cultivating communities of practice: A guide to managing knowledge. Harvard Business Press, 2002.

[23] E. Wenger, Communities of practice: Learning, meaning, and identity. Cambridge university press, 1999.

[24] M. Paasivaara and C. Lassenius, "Communities of practice in a large distributed agile software development organization-case ericsson," Information and Software Technology, vol. 56, no. 12, pp. 1556-1577, 2014. 